\title{
MicroRNA 452 Regulates Cell Proliferation, Cell Migration, and Angiogenesis in Colorectal Cancer by Suppressing VEGFA Expression
}

\author{
Ji Su Mo ${ }^{1,2}$, Won Cheol Park ${ }^{2}$, Suck-Chei Choi ${ }^{2}$, Ki Jung Yun ${ }^{1,2}$ and Soo-Cheon Chae ${ }^{1,2, *}$ \\ 1 Department of Pathology, School of Medicine, Wonkwang University, Iksan, Chonbuk 54538, Korea; \\ siuale97@hanmail.net (J.S.M.); kjyun@wku.ac.kr (K.J.Y.) \\ 2 Digestive Disease Research Institute, Wonkwang University, Iksan, Chonbuk 54538, Korea; \\ parkwc@wku.ac.kr (W.C.P.); medcsc@wku.ac.kr (S.-C.C.) \\ * Correspondence: chaesc@wku.ac.kr; Tel.: +82-63-8506793; Fax: +82-63-8506760
}

Received: 25 September 2019; Accepted: 18 October 2019; Published: 22 October 2019

\begin{abstract}
The human microRNA 452 (MIR452) was identified as a colorectal cancer (CRC)-associated micro RNA (miRNA) by miRNA expression profiling of human CRC tissues versus normal colorectal tissues. It was significantly up-regulated in human CRC tissues. However, the functional mechanisms of MIR452 and its target genes in CRC remain unclear. We identified 27 putative MIR452 target genes, and found that the vascular endothelial growth factor A (VEGFA) was a direct target gene of MIR452. Both cellular and extracellular VEGFA levels were significantly downregulated in CRC cells upon their transfection with MIR452 or siVEGFA. VEGFA expression was frequently downregulated in human $\mathrm{CRC}$ tissues in comparison with that in their healthy counterparts. We showed that MIR452 regulated the expression of genes in the VEGFA-mediated signal transduction pathways vascular endothelial growth factor receptor 1 (VEGFR2)-mitogen-activated protein kinase (MAPK) and VEGFR2-SRC proto-oncogene non-receptor tyrosine kinase (SRC) in CRC cells. Immunohistological analyses of xenografted MIR452-overexpressing CRC cells in mice showed that MIR452 regulated cell proliferation and angiogenesis. Furthermore, aortic ring angiogenesis assay in rats clearly showed that the number of microvessels formed was significantly reduced by MIR452 transfection. Our findings suggest that MIR452 regulates cell proliferation, cell migration, and angiogenesis by suppressing VEGFA expression in early CRC progression; therefore, MIR452 may have therapeutic value in relation to human CRC.
\end{abstract}

Keywords: microRNA; MIR452; VEGFA; VEGFR2; angiogenesis; colorectal cancer

\section{Introduction}

Colorectal cancer (CRC) is the third most prevalent type of cancer worldwide [1]. The cause of $\mathrm{CRC}$ is multifactorial, including genetic variation and epigenetic and environmental factors such as diet, microbiome, and their metabolites [2]. However, the precise molecular mechanism underlying the development and progression of CRC remains largely unknown. Therefore, it is of great importance to elucidate the molecular mechanisms and genes underlying CRC tumorigenesis.

MicroRNAs (miRNAs) are endogenously expressed small noncoding RNA molecules that mostly bind to the $3^{\prime}$ untranslated regions (UTR) of their target mRNAs, thereby regulating gene expression in multicellular organisms post-transcriptionally by controlling the stability or translation of target mRNAs [3]. MiRNAs regulate crucial biological processes, such as cell proliferation, apoptosis, and differentiation as well as angiogenesis [4-7]. They also affect the pathogenesis of various cancer types by functioning as oncogenes or tumor suppressor genes [8-11]. More recently, accumulating reports suggest that miRNAs are associated the various forms of tumorigenesis including lung cancer [12-14], 
prostate cancer $[15,16]$, gastric cancer $[17,18]$, and liver cancer $[19,20]$. Therefore, characterization of the correlations between miRNAs and their target genes in cancer cells may have a substantial diagnostic, prognostic, and therapeutic value.

MicroRNA 452 (MIR452, also known as has-miR-452) is encoded by the chromosomal region Xq28 in humans and clustered together with MIR224 within the gamma-aminobutyric acid A receptor epsilon subunit (GABRE) gene. Several studies have suggested that MIR452 expression is downregulated in human breast cancer [21], glioma [22], and hepatocellular carcinoma (HCC) [23]. However, in other studies, MIR452 has been found to be upregulated in hepatocellular carcinomas [24] and lymph node-positive urothelial carcinomas [25], suggesting that MIR452 can have diverse roles in distinct types of human cancers or cells. In our previous study, MIR452 was found to be upregulated in both CRC [26] and colitis [27] by differential miRNA expression profiling of human CRC tissues and dextran sulfate sodium (DSS)-induced mouse colitis tissues, respectively.

In this study, we identified the target genes of MIR452 and analyzed their functions in human CRC cell lines and colorectal tissues. The candidate MIR452 target genes were identified by microarray-based differential mRNA expression profiling of MIR452-overexpressing CRC cells. These candidates were shortlisted by comparing the mRNA microarray results for the candidate target genes predicted by bioinformatics tools. We identified vascular endothelial growth factor A (VEGFA, also known as VPF, $V E G F$, or MVCD1) as a MIR452 target gene in CRC, and analyzed the correlation between MIR452 and VEGFA using human CRC tissues, cell lines, and xenograft tumors, as well as rat aortas. Overall, we demonstrated that MIR452 regulates cell proliferation and migration as well as angiogenesis in CRC by suppressing VEGFA expression.

\section{Results}

\subsection{MIR452 Expression Level in Human CRC Tissues and Cell Lines}

We have previously found that MIR452 is upregulated in human CRC tissues [26]. To confirm this result, we compared the MIR452 levels in 10 human CRC tissue samples with those in matching healthy colon tissues by qRT-PCR. MIR452 levels were increased in CRC tissues (7 out of 10, Figure S1A). To determine the levels of endogenous MIR452 in CRC cell lines such as SW480, HT29, Caco2, HCT116, Lovo, and SW48 cells, we carried out qRT-PCR analysis using the total RNAs isolated from each cell lines. The MIR452 level was lowest in SW480 cells and highest in HT29 cells (Figure S1B).

\subsection{Differential mRNA Expression Profiling of MIR452-Overexpressing Cells}

To identify the genes downregulated by MIR452 overexpression, a MIR452 mimic was transfected into SW480 and Caco 2 cells. Increased MIR452 level $24 \mathrm{~h}$ after the transfection confirmed the transfection efficiency (Figure S1C). The cells were harvested $48 \mathrm{~h}$ after the transfection for mRNA expression profiling with the Illumina HumanHT-12 v4 Expression BeadChip. We identified 261 genes whose levels were 1.3-fold downregulated in MIR452-overexpressing cells (Table S1).

\subsection{Identification of the MIR452 Target Genes}

The 261 genes identified by mRNA microarray analysis in MIR452-overexpressing cells were compared with the candidate MIR452 target genes predicted by TargetScan and miRWalk algorithms. Of the 261 genes, 27 genes were finally identified as putative direct targets of MIR452 (Table 1). Among them, we focused on VEGFA. We observed that SW480 and SW48 cells had the lowest and highest endogenous VEGFA levels, respectively (Figure S1D). 
Table 1. The putative target genes of microRNA 452 (MIR452) identified and predicted by both the microarray analysis from the MIR452-overexpressed cells and the bioinformatics methods.

\begin{tabular}{|c|c|c|c|c|}
\hline $\begin{array}{l}\text { Gene } \\
\text { Symbol }\end{array}$ & Accession & Gene Name & $\begin{array}{l}\text { Chromosome } \\
\text { Location }\end{array}$ & Functions \\
\hline ARGLU1 & NM_018011 & arginine and glutamate rich 1 & $13 q 33.3$ & - \\
\hline ASB8 & NM_024095 & $\begin{array}{c}\text { ankyrin repeat and SOCS box } \\
\text { containing } 8\end{array}$ & $12 q 13.11$ & - \\
\hline BCAS2 & NM_005872 & $\begin{array}{l}\text { breast carcinoma amplified } \\
\text { sequence } 2\end{array}$ & $1 \mathrm{p} 13.2$ & - \\
\hline BTF3L4 & NM_152265 & $\begin{array}{l}\text { basic transcription factor } \\
\text { 3-like } 4\end{array}$ & $1 \mathrm{p} 32.3$ & - \\
\hline CDK5R1 & NM_003885 & $\begin{array}{l}\text { cyclin-dependent kinase } 5, \\
\text { regulatory subunit } 1\end{array}$ & 17q11.2 & $\begin{array}{l}\text { neuron-specific } \\
\text { activator }\end{array}$ \\
\hline CLK1 & NM_004071 & CDC-like kinase 1 & $2 q 33$ & protein kinases \\
\hline DCUN1D1 & NM_020640 & $\begin{array}{l}\text { DCN1, defective in cullin } \\
\text { neddylation } 1 \text {, domain } \\
\text { containing } 1\end{array}$ & $3 q 26.3$ & - \\
\hline FAM134B & NM_001034850 & $\begin{array}{l}\text { family with sequence } \\
\text { similarity } 134 \text {, member B }\end{array}$ & $5 p 15.1$ & $\begin{array}{l}\text { transmembrane } \\
\text { protein (Golgi) }\end{array}$ \\
\hline FAM8A1 & NM_016255 & $\begin{array}{l}\text { family with sequence } \\
\text { similarity } 8 \text {, member A1 }\end{array}$ & $6 \mathrm{p} 23$ & - \\
\hline FBXW5 & NM_018998 & $\begin{array}{c}\text { F-box and WD repeat domain } \\
\text { containing } 5\end{array}$ & $9 q 34.3$ & ubiquitination \\
\hline GTF2E1 & NM_005513 & $\begin{array}{c}\text { general transcription factor IIE, } \\
\text { polypeptide } 1 \text {, alpha } 56 \mathrm{kDa}\end{array}$ & $3 q 21-q 24$ & transcription factor \\
\hline GTF2H1 & NM_005316 & $\begin{array}{l}\text { general transcription factor } \\
\text { IIH, polypeptide } 1,62 \mathrm{kDa}\end{array}$ & 11p15-p14 & transcription factor \\
\hline IL20RA & NM_014432 & $\begin{array}{l}\text { interleukin } 20 \text { receptor } \\
\text { subunit alpha }\end{array}$ & $6 \mathrm{q} 23.3$ & cytokine receptor \\
\hline METTL10 & NM_212554 & methyltransferase like 10 & $10 \mathrm{q} 26.13$ & - \\
\hline MTFR1 & NM_014637 & $\begin{array}{l}\text { mitochondrial fission } \\
\text { regulator } 1\end{array}$ & $8 \mathrm{q} 13.1$ & $\begin{array}{l}\text { mitochondrial } \\
\text { protein }\end{array}$ \\
\hline NOL8 & NM_017948 & nucleolar protein 8 & 9 p22.31 & - \\
\hline PER2 & NM_022817 & period circadian clock 2 & $2 q 37.3$ & - \\
\hline PKN2 & NM_006256 & protein kinase $\mathrm{N} 2$ & $1 \mathrm{p} 22.2$ & - \\
\hline PLEKHA1 & NM_001001974 & $\begin{array}{l}\text { pleckstrin homology domain } \\
\text { containing, family A }\end{array}$ & $10 \mathrm{q} 26.13$ & adapter protein \\
\hline PPL & NM_002705 & periplakin & $16 \mathrm{p} 13.3$ & $\begin{array}{c}\text { desmosomes } \\
\text { component }\end{array}$ \\
\hline SHC1 & NM_001130040 & SHC adaptor protein 1 & $1 \mathrm{q} 21.3$ & adapter protein \\
\hline TAF5L & NM_001025247 & $\begin{array}{l}\text { TATA-box binding protein } \\
\text { associated factor } 5 \text { like }\end{array}$ & $1 \mathrm{q} 42.13$ & $\begin{array}{l}\text { histone } \\
\text { acetylase complex }\end{array}$ \\
\hline THNSL2 & NM_018271 & threonine synthase-like 2 & $2 \mathrm{p} 11.2$ & threonine synthase \\
\hline THUMPD1 & NM_017736 & THUMP domain containing 1 & $16 \mathrm{p} 12.3$ & - \\
\hline TMPRSS2 & NM_005656 & $\begin{array}{l}\text { transmembrane protease, } \\
\text { serine } 2\end{array}$ & $21 \mathrm{q} 22.3$ & serine protease \\
\hline VEGFA & NM_001025366 & $\begin{array}{l}\text { vascular endothelial growth } \\
\text { factor A }\end{array}$ & $6 \mathrm{p} 12$ & growth factor \\
\hline WTAP & NM_004906 & $\begin{array}{l}\text { Wilms tumor } 1 \\
\text { associated protein }\end{array}$ & $6 q 25-q 27$ & $\begin{array}{c}\text { tumor } \\
\text { suppressor gene }\end{array}$ \\
\hline
\end{tabular}




\subsection{VEGFA Was a Direct Target of MIR452}

To assess whether MIR452 directly interacts with VEGFA 3'-UTR, we cloned wild type (WT) VEGFA 3'-UTR (predicted to interact with MIR452) into a luciferase reporter vector (Figure 1A). The luciferase intensity was reduced by approximately $15 \%$ when the cells were co-transfected with a MIR452 mimic $(p<0.01$, Figure 1B). As a negative control, a MIR1 mimic instead of the MIR452 mimic was co-transfected with the wild WT VEGFA 3'-UTR construct. The MIR1 mimic did not affect the luciferase activity (Figure 1B). As an additional negative control, we also cloned a mutated (MT) version of VEGFA 3'-UTR whose eight of the bases complementary to MIR452 were substituted (Figure 1A). As expected, the luciferase activity did not change (Figure 1B). Next, we tested whether MIR452 regulated VEGFA mRNA and protein levels in Caco2 cells. The VEGFA mRNA level was lower in Caco2 cells transfected with the MIR452 mimic than in un-transfected control cells ( $p<0.05$; Figure 1C). The cellular VEGFA protein levels were also significantly reduced in the MIR452-overexpressing cells $(p<0.01$; Figure 1C). These results indicate that VEGFA is a direct target of MIR452.

A

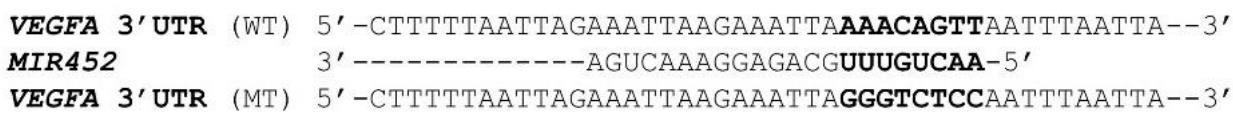

B

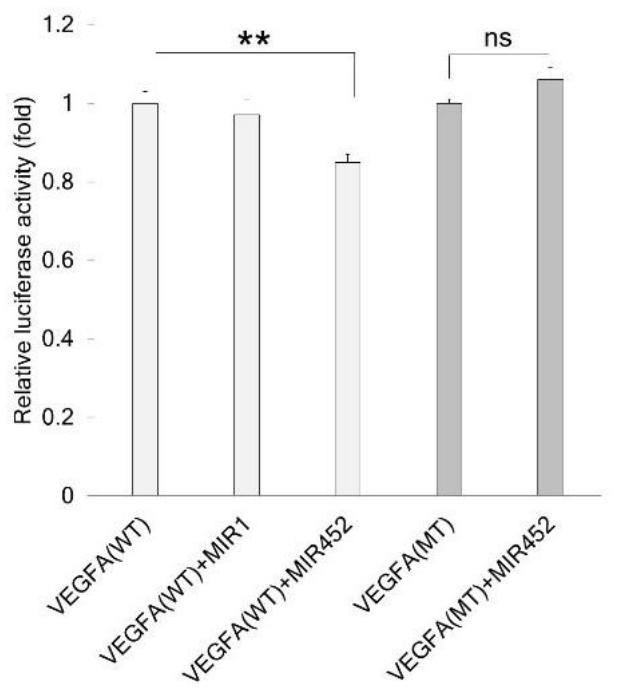

C
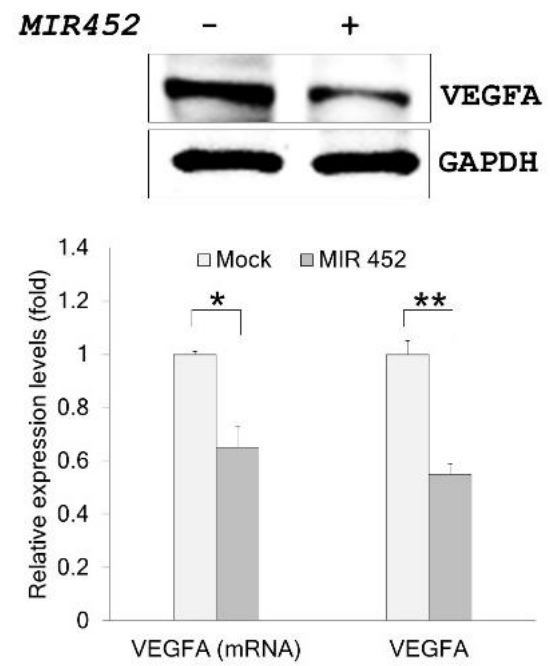

Figure 1. VEGFA was a direct target of MIR452. (A) Sequence alignment of the wild type (WT) and mutated (MT) MIR452 target sites in the 3'-UTR of VEGFA. A human VEGFA 3'-UTR containing the WT and MT MIR452 binding site was cloned downstream of a luciferase reporter gene. (B) The luciferase reporter plasmid containing the WT or MT VEGFA 3'-UTR was co-transfected into Caco2 or HT29 cells with the MIR1 mimic (negative control) or MIR452 mimic. Luciferase activity was determined by the dual luciferase assay. Results are shown as the relative firefly luciferase activity normalized to the Renilla luciferase activity. Data represent three independent experiments with the Caco2 cells. (C) VEGFA mRNA and protein levels in the mock- and MIR452 mimic-transfected Caco2 cells. Protein or mRNA was extracted 72 or $48 \mathrm{~h}$ after transfection, respectively, and the samples were subjected to western blotting or qRT-PCR. Data represent three independent experiments. Statistical differences were calculated using Student's $t$-test (ns $=$ not significant; ${ }^{*} p<0.05$; ${ }^{* *} p<0.01$ ).

\subsection{VEGFA Expression in Human CRC Tissues}

On the basis of the findings described above, we evaluated VEGFA expression in additional 10 human CRC tissues and matching healthy colon tissues by western blotting. VEGFA protein expression was found to be decreased in CRC tissues in 8 of the 10 pairs (Figure 2A). 
The finding described above (Figure S1A and Figure 2A) prompted us to evaluate VEGFA expression in different tumor $(\mathrm{T})$ stages of human CRC and the matching healthy colon tissues by immunohistochemistry. VEGFA level was significantly lower in the T1 and T2 stage CRC tissues relative to that in the matching healthy colon tissues. However, VEGFA level dramatically increased in the T3 stage CRC tissue and no difference was observed at the T4 stage (Figure 2B).

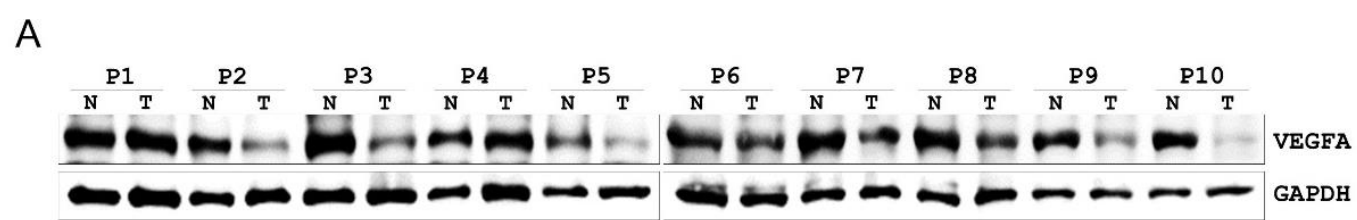

B
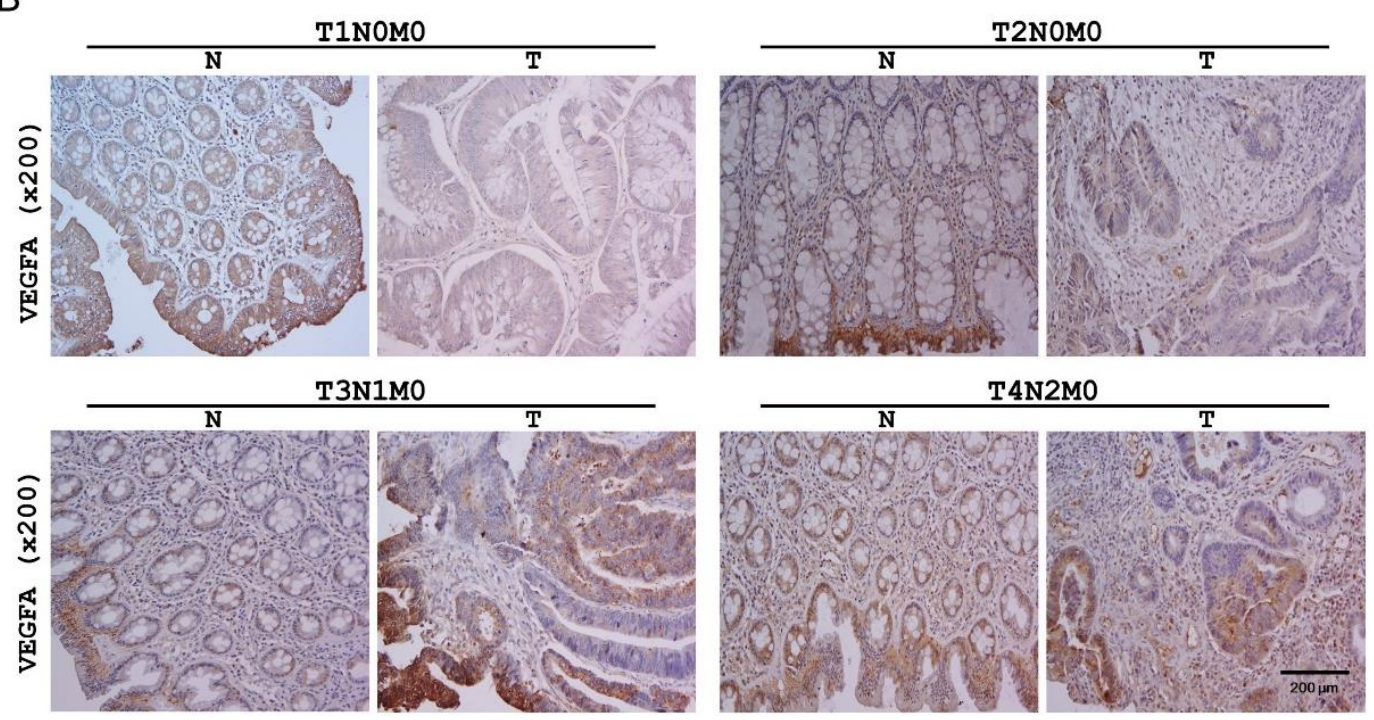

Figure 2. Endogenous VEGFA levels in human colorectal cancer (CRC) tissues. (A) The expression levels of VEGFA were validated using 10 pairs of human CRC and adjacent healthy colorectal samples by western blotting. The expression levels were normalized to that of Glyceraldehyde 3-phosphate dehydrogenase (GAPDH). (B) VEGFA immunostaining in the TNM Classification of Malignant Tumors (TNM) stage human CRC and adjacent healthy colorectal samples (200× magnification). These experiments were independently performed three times in duplicate.

\subsection{MIR452 Regulated the VEGFA-Vascular Endothelial Growth Factor Receptor (VEGFR) Signaling} Pathway in CRC Cells

We then determined which VEGFA receptor is mainly regulated by MIR452 using MIR452transfected Caco2 cells. VEGFR2 $(p<0.05)$ was more significantly affected by MIR452 overexpression than VEGFR1 (Figure 3A). Downregulation of VEGFR2 by MIR452 overexpression was also validated in HT29 cells ( $p<0.05$; Figure 3B).

To determine the functional significance of the interaction between MIR452 and VEGFR2 in Caco2 cells, we analyzed the expression levels of several proteins involved in the signal transduction pathway downstream of VEGFR2 by western blot analysis. Proto-oncogene non-receptor tyrosine kinase (SRC), phospholipase C gamma 1 (PLCG1), and mitogen-activated protein kinase (MAPK) levels were significantly reduced by MIR452 transfection in Caco2 cells $(p<0.01, p<0.01$, and $p<0.05$, respectively; Figure 3C). However, phosphatidylinositol-4,5-bisphosphate 3-kinase catalytic subunit alpha (PIK3CA) and heat shock protein family B member 1 (HSPB1) levels did not change by MIR452 transfection (Figure 3C). We also obtained similar results by knocking down VEGFA in Caco2 cells through VEGFA gene silencing (siVEGFA) transfection (Figure 3C). These results indicated that MIR452 
regulated the VEGFA-VEGFR2-mediated SRC, PLCG1, and MAPK signal transduction pathways, but not PIK3CA or HSPB1 signaling in CRC cells.

A

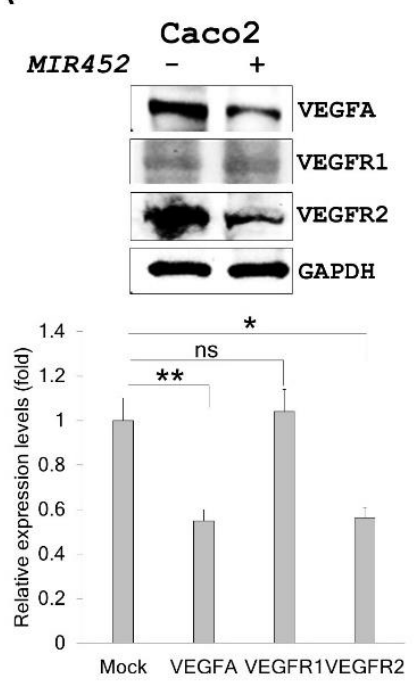

B

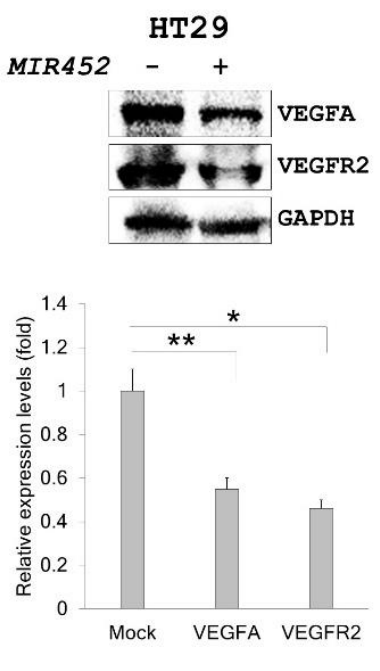

C
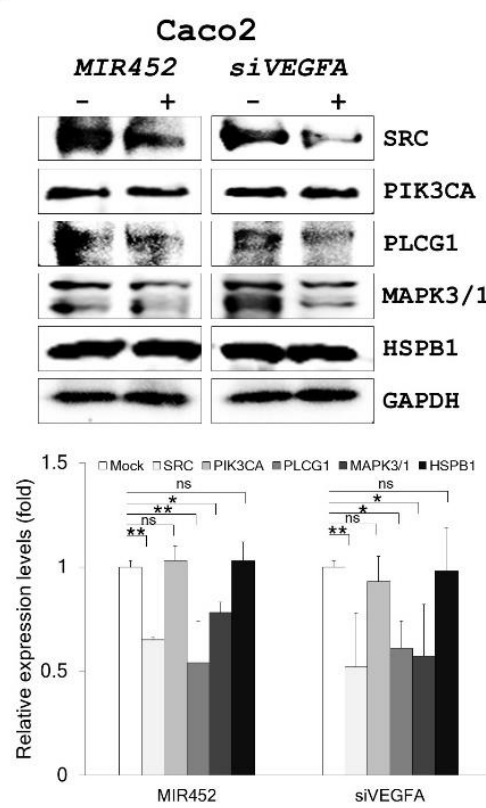

Figure 3. Expression levels of the target and downstream genes in MIR452-overexpressing CRC cells. (A) The expression levels of VEGFR1 and VEGFR2 in Caco2 cells upon MIR452 overexpression. (B) The VEGFR1 and VEGFR2 expression levels in MIR452-overexpressing HT29 cells. (C) Proto-oncogene non-receptor tyrosine kinase (SRC), phosphatidylinositol-4,5-bisphosphate 3-kinase catalytic subunit alpha (PIK3CA), phospholipase C gamma 1 (PLCG1), mitogen-activated protein kinase (MAPK), and heat shock protein family B member 1 (HSPB1) expression levels in Caco2 cells transfected with the MIR452 mimic or VEGFA gene silencing (siVEGFA). Three independent experiments were performed with duplicates, and the statistical differences were calculated using Student's $t$-test (ns = not significant; $\left.{ }^{*} p<0.05 ;{ }^{* *} p<0.01\right)$.

\subsection{MIR452 Regulated VEGFA-Mediated VEGFR2-SRC-Protein Tyrosine Kinase 2 (PTK2) Signaling}

On the basis of the above results, we tested whether VEGFA downregulation by the MIR452 mimic or SiVEGFA affected the VEGFR2-SRC-PTK2 signaling pathway in CRC cells. Western blotting results showed that SRC $(p<0.01)$ and PTK2 $(p<0.01)$ were markedly downregulated by both MIR452 mimic and siVEGFA transfections in Caco2 and SW48 cells (Figure 4A,B). These findings suggested that MIR452 regulated the VEGFA-mediated VEGFR2-SRC-PTK2 signaling pathway.

\subsection{Migration of the Cells Transfected with the MIR452 Mimic or siVEGFA}

As shown in Figure 4C, scratch wound assay showed that migration of HT29 cells was significantly suppressed upon transfection with the MIR452 mimic or siVEGFA (Figure $4 \mathrm{C}, p<0.01$ ). Likewise, migration of $\mathrm{Caco} 2$ and HT29 cells through the Transwell filters was also significantly suppressed by the MIR452 mimic (Figure 4D, $p<0.05$ ). These results suggested that MIR452 regulated cell migration by the VEGFA-mediated VEGFR2-SRC-PTK2 signaling pathway in CRC cells. 
A

\section{$\mathrm{Caco} 2$}
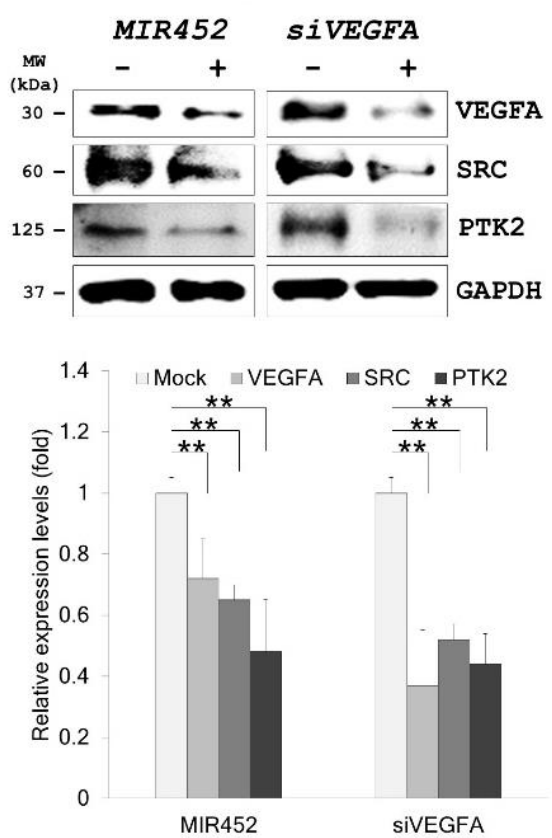

C

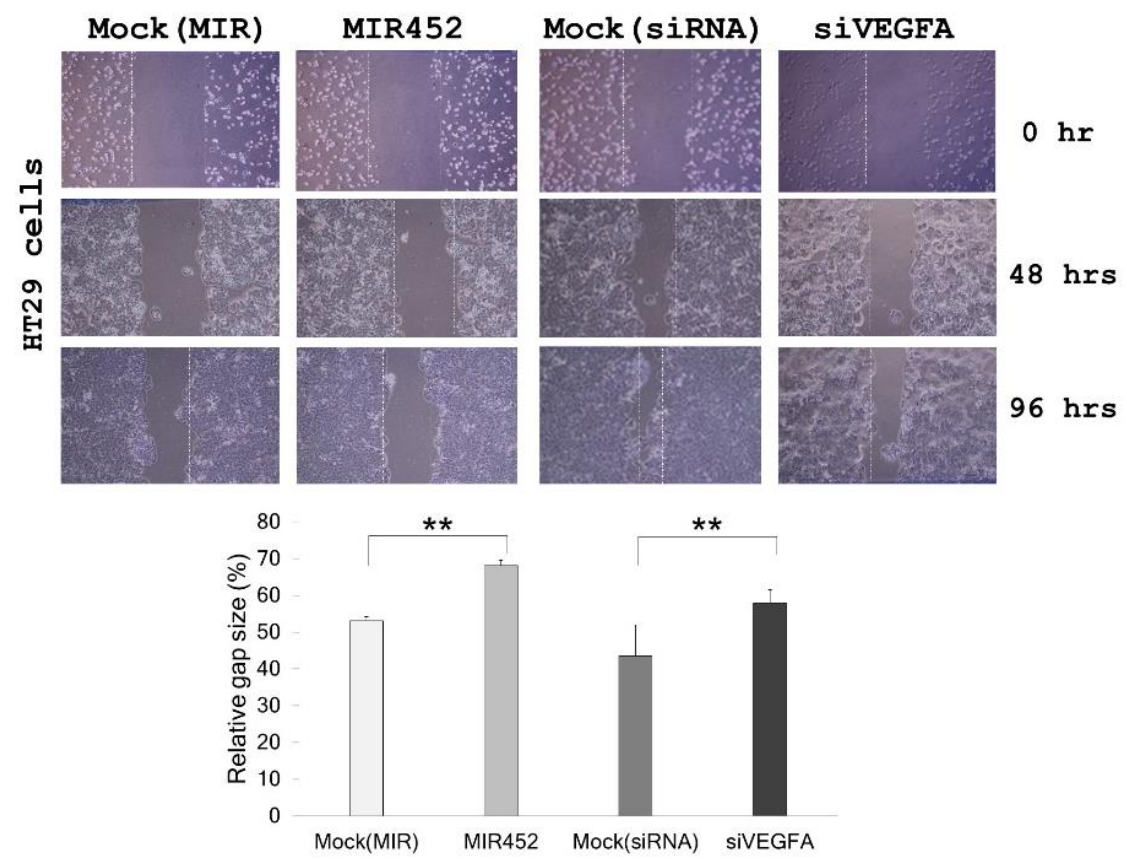

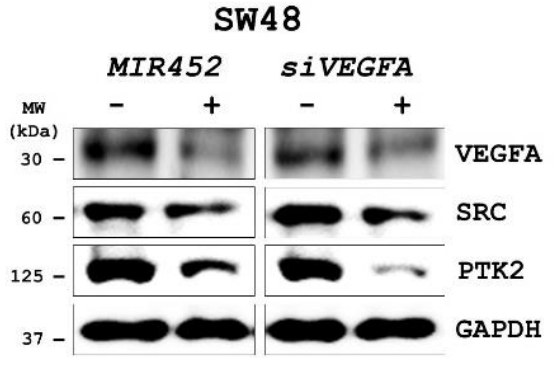

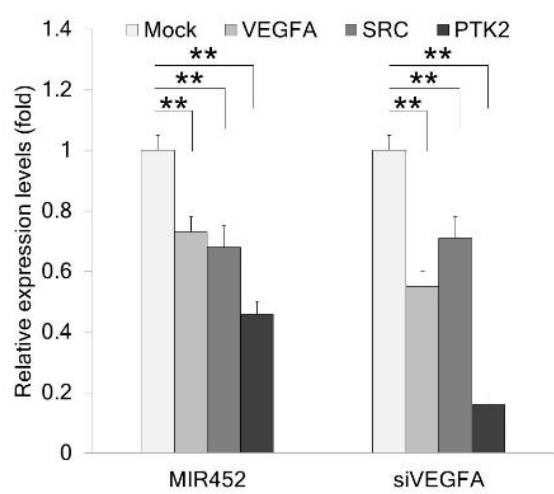

Figure 4. Cont. 
D

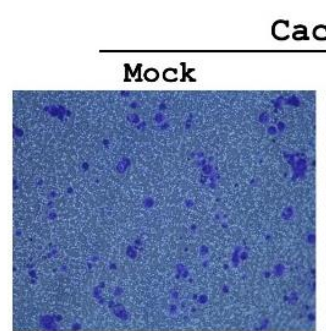

$\operatorname{Caco} 2$
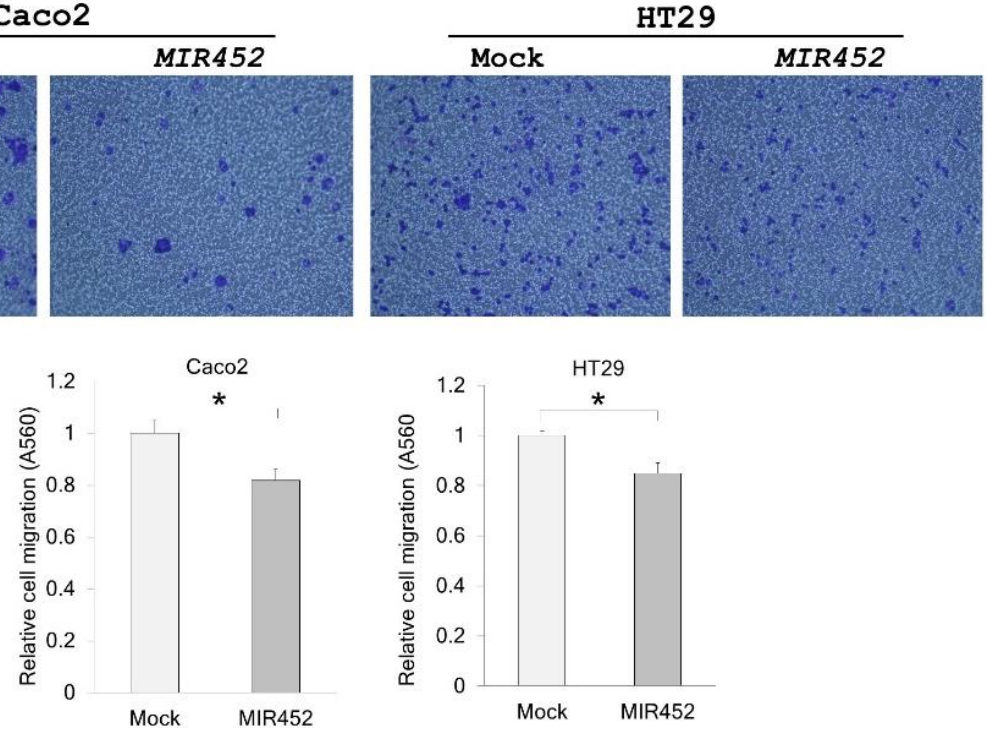

Figure 4. MIR452 regulated VEGFA-mediated VEGFR2-SRC signaling in CRC cells. (A) Western blot analysis of VEGFR2-regulated proteins, SRC and protein tyrosine kinase 2 (PTK2), in Caco2 cells. (B) Western blot analysis of SRC and PTK2 in SW48 cells. Three independent experiments were performed in duplicate, and the $p$-values were calculated using Student's $t$-test $(* * p<0.01)$. (C) The scratch wound assay was conducted using HT29 cells transfected with the MIR452 mimic, siVEGFA, or mock controls. The migration distance was measured 0,48 , and $96 \mathrm{~h}$ after the cells were scratched. Three independent experiments were performed in duplicate, and the $p$-values were calculated using Student's $t$-test (** $p<0.01$ ). (D) For the migration assay, we used 24-well Transwell chambers, which separated the upper and lower compartments by polycarbonate membranes that consisted of $8 \mu \mathrm{m}$ pores. The cells that retained the dye were quantified by measuring absorbance at $560 \mathrm{~nm}$ (A560). Compared with the mock control, the MIR452 mimic reduced migration of both Caco2 and HT29 cells. Three independent experiments were performed with duplicates, and the $p$-values were calculated using Student's $t$-test $\left({ }^{*} p<0.05\right)$.

\subsection{MIR452 Regulated VEGFA-Mediated VEGFR2-KRAS GTPase Proto-Oncogene (KRAS)-B-Raf} Proto-Oncogene, Serine/Threonine Kinase (BRAF) Signaling

To further investigate the effect of MIR452 or SiVEGFA on VEGFR2-KRAS signaling, we assessed the expression levels of the proteins downstream of KRAS in Caco2 cells transfected with the MIR452 mimic or siVEGFA. Western blotting results showed that KRAS $(p<0.01)$, BRAF $(p<0.05$ and 0.01 , respectively), and MAPK $(p<0.01)$ levels were markedly downregulated by both MIR452 mimic and siVEGFA transfections in Caco2 cells (Figure 5A). We also performed the same analyses in SW48 cells. Caco2 and SW48 cells both express KRAS and BRAF [28]. The results showed that KRAS $(p<0.01)$, BRAF $(p<0.05)$, and MAPK $(p<0.05)$ levels were significantly downregulated by both MIR452 mimic and siVEGFA transfections in SW48 cells (Figure 5B). These results clearly indicated that MIR452 regulated the VEGFA-mediated VEGFR2-KRAS-BRAF signaling pathway in CRC cells.

\subsection{MIR452 Inhibited CRC Cell Proliferation}

The above results led us to explore the biological function(s) of MIR452 in CRC cells. 3-(4,5-dimethylthiazol-2-yl)-2,5-diphenyl tetrazolium bromide (MTT) assay showed that cell viability was stably reduced by transfection of the CRC cell lines Caco2 $(p<0.001)$ and SW48 $(p<0.001$; Figure 5C) with the MIR452 mimic. Similar results were obtained with VEGFA gene silencing (siVEGFA) in CRC cells $(p<0.001$; Figure 5C). These results indicated that MIR452 suppressed proliferation of CRC cells by inhibiting VEGFA expression. 
A
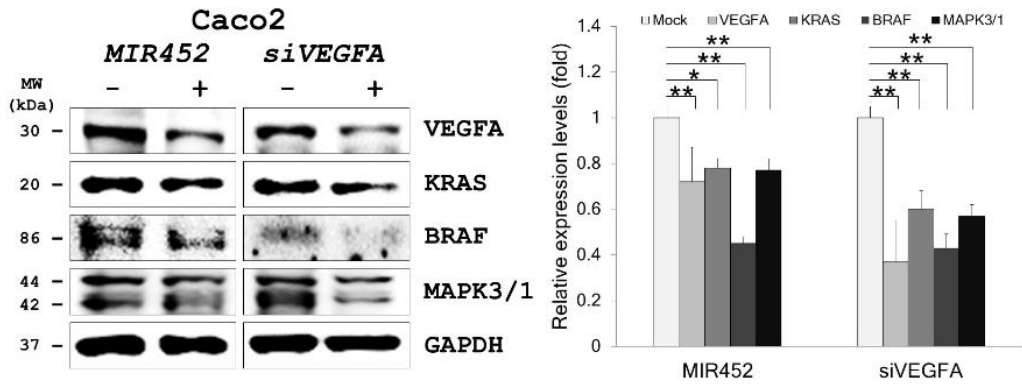

B
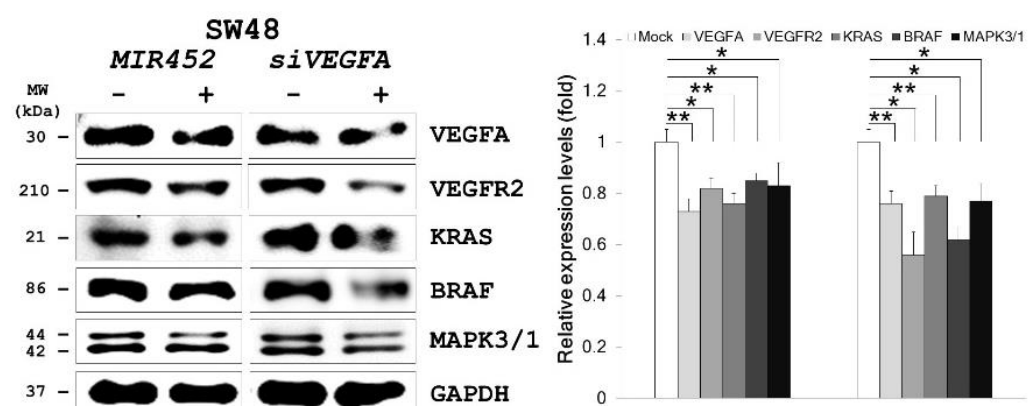

C
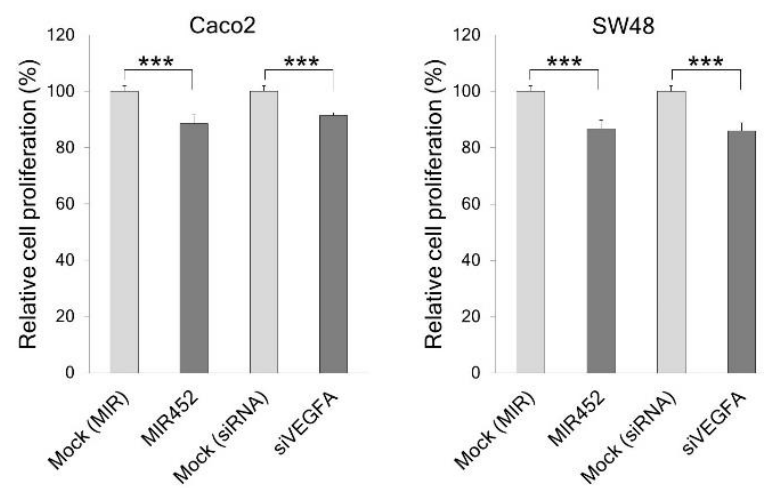

Figure 5. MIR452 regulated VEGFA-mediated VEGFR2-KRAS GTPase proto-oncogene (KRAS) signaling in CRC cells. (A) Western blot analysis of VEGFR2-regulated proteins KRAS, B-Raf proto-oncogene, serine/threonine kinase (BRAF), and MAPK in Caco2 cells transfected with the MIR452 mimic or siVEGFA. (B) Western blot analysis of KRAS, BRAF, and MAPK in SW48 cells transfected with the MIR452 mimic or siVEGFA. Four independent experiments were performed in duplicate, and the $p$-values were calculated using Student's $t$-test $\left.{ }^{*} p<0.05 ;{ }^{* *} p<0.01\right)$. (C) Viability of Caco2 and SW48 cells transfected with the MIR452 mimic or siVEGFA. Cell viability was determined by the MTT assay. Three independent experiments were performed in duplicate, and the $p$-values were calculated by using Student's $t$-test $\left({ }^{* * *} p<0.001\right)$.

\subsection{Effect of MIR452 on the Growth of Xenografted CRC Cells in Mice}

To study the effect of MIR452 on tumor growth in vivo, we used a xenograft tumor model consisting of athymic nude mice with subcutaneously implanted HT29 cells. After 21 days of transfection, the mean tumor volume of the MIR452-transfected cells was $306.1 \pm 42.8 \mathrm{~mm}^{3}$, which was significantly smaller than that of the tumor made of the mock control cells $\left(555.1 \pm 30.7 \mathrm{~mm}^{3}\right.$; Figure 6A upper panel and Figure 6B). Additionally, relative to the tumor size of the mock control cells $\left(460.9 \pm 59.1 \mathrm{~mm}^{3}\right)$, the average tumor size of siVEGFA-transfected cells $\left(296.8 \pm 44.8 \mathrm{~mm}^{3}\right)$ was significantly smaller (Figure 6A bottom panel and Figure 6B). These results indicated that the tumor cell growth was reduced by MIR452 overexpression in CRC cells. 


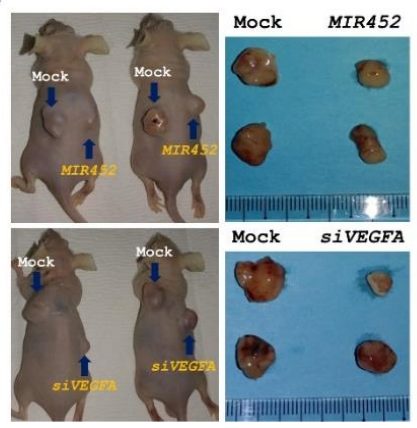

B

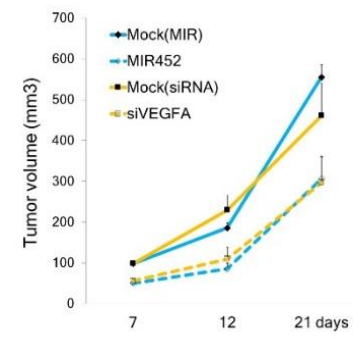

C

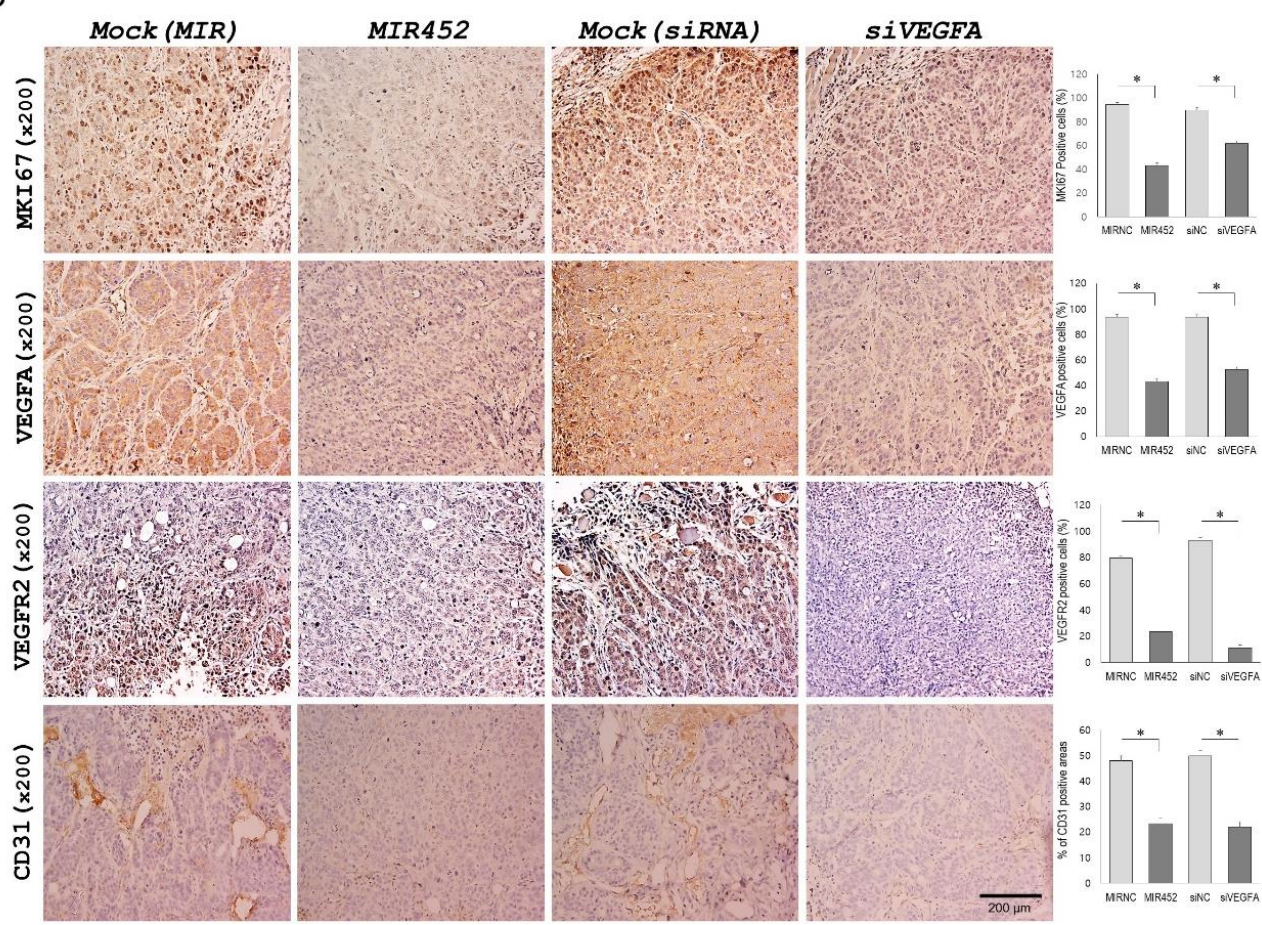

Figure 6. MIR452 inhibited CRC cell growth and angiogenesis in the xenograft model. (A) MIR452 inhibited CRC cell growth in vivo. An image of xenograft tumors derived from HT29 cells transfected with the MIR452 mimic or mock control (upper panel), and the siVEGFA or mock control (bottom panel). (B) Volumes of the xenograft tumors derived from HT29 cells transfected with the MIR452 mimic, siVEGFA, or mock controls in nude mice. $(n=8$, mean $\pm \mathrm{SD})$. Three independent experiments were performed using 2-3 mice per experiment. (C) Expression of the cell proliferation marker MKI67 (the top column), VEGFA (the second column from the top), VEGFR2 (the third column from the top), and endothelial cell marker CD31 (the fourth column from the top) in the xenograft tumors formed after subcutaneous transplantation of HT29 cells transfected with the MIR452 mimic, siVEGFA, or mock controls (200× magnification). Three independent experiments were performed in duplicate, and the $p$-values were calculated by using Student's $t$-test $\left({ }^{*} p<0.05\right)$.

\subsection{Histopathology of the Tumors Derived from the Xenografts of MIR452-Transfected CRC Cells}

The xenograft tumors were immunohistochemically analyzed using antibodies against monoclonal antibodies against the proliferation marker Ki-67 (MKI67), VEGFA, VEGFR2, and CD31. The xenograft tumors derived from MIR452 mimic- or siVEGFA-transfected HT29 cells contained significantly less MKI67-positive cells compared with the mock control tumors ( $p<0.05$; Figure 6 C, the top column). We evaluated the VEGFA and VEGFR2 levels in the mice bearing the HT29 xenografts. MIR452 mimic or siVEGFA-transfected tumors contained significantly decreased VEGFA and VEGFR2 expression compared with mock control tumors $(p<0.05$; Figure $6 \mathrm{C}$, the second and third columns from 
the top). We also checked the effect of MIR452 on angiogenesis in mice bearing HT29 xenografts. Immunohistochemical staining of CD31 revealed that the blood vessel network was well developed in the mock control tumor but appeared to have been inhibited by the MIR452 mimic or siVEGFA $(p<0.05$; Figure 6C, the fourth column from the top). These results suggested that MIR452 regulated cell proliferation and angiogenesis in the CRC cell-derived xenograft tumors by inhibiting VEGFA expression.

\subsection{MIR452 Inhibited Angiogenesis by VEGFA Downregulation in the Rat Aortic Ring Model}

To further define the correlation between MIR452-VEGFA and angiogenesis, we investigated the extracellular VEGFA levels in MIR452 mimic- or siVEGFA-transfected Caco2 and SW48 cells. The extracellular (secreted into the culture media) VEGFA levels were also significantly reduced by the transfection of Caco2 and SW48 cells with the MIR452 mimic or siVEGFA $(p<0.01$; Figure 7A).

\section{A}
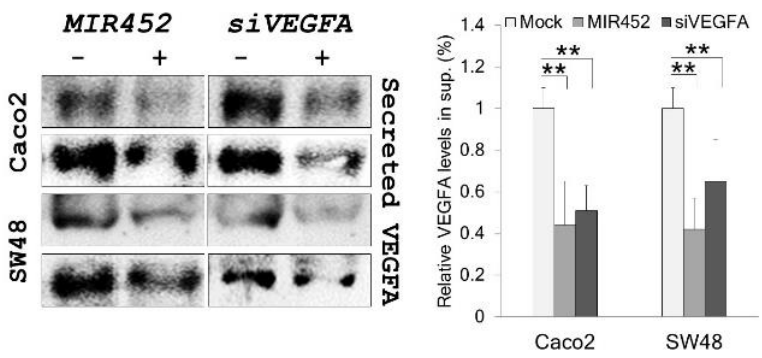

B
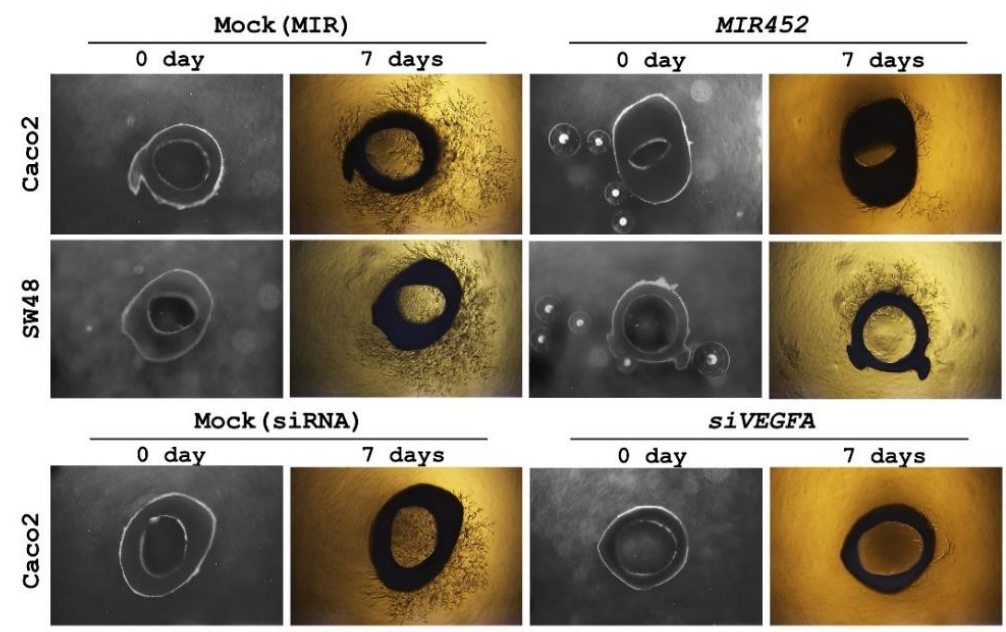

VEGFA
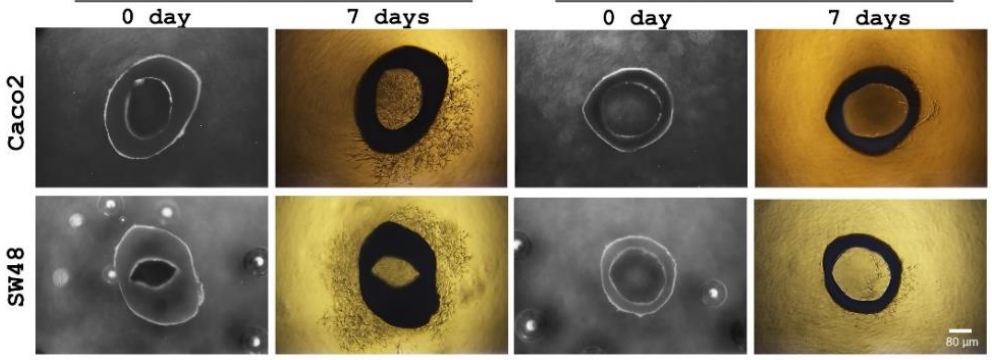

Figure 7. MIR452 regulated angiogenesis by extracellular VEGFA secretion. (A) The extracellular VEGFA levels in Caco2 and SW48 cells transfected with the MIR452 mimic, siVEGFA, or mock controls. Three independent experiments were performed in duplicate, and the $p$-values were calculated using Student's $t$-test $(* * p<0.01)$. (B) Rat aortic ring angiogenesis assay. The aortic rings from four-week-old Sprague-Dawley rats were randomly seeded onto Matrigel-coated wells and sealed with an overlay of Matrigel. They were co-cultured with Caco2 or SW48 cells transfected with the MIR452 mimic (upper panel), siVEGFA (bottom panel), or mock controls. After 7 days, microvessel sprouting was photographed using an inverted microscope (Olympus; $2.5 \times$ magnification). Four independent experiments were performed in duplicate. 
On the basis of the above results, we investigated the role of VEGFA secreted from Caco2 and SW48 cells transfected with the MIR452 mimic or SiVEGFA in an aortic angiogenesis model. After 7 days of co-culture, the microvessel formation by MIR452 mimic-transfected Caco 2 and SW48 cells was significantly less than that observed in the mock controls (Figure 7B, upper panel). We also observed similar results with siVEGFA-transfected CRC cells (Figure 7B, bottom panel). These results clearly indicated that MIR452 regulates aortic angiogenesis through VEGFA signaling.

\section{Discussion}

MiRNAs have been implicated as important post-transcriptional regulators in various biological processes as well as in the pathogenesis of various cancer types as tumor suppressor genes or oncogenes $[4,8,9]$. It has been well accepted that miRNAs exert their effects through their target genes. In fact, accumulating studies have recently suggested that miRNAs are essential for the tumorigenesis stages of human CRC, including cancer initiation and proliferation, apoptosis, angiogenesis, epithelial-mesenchymal transition (EMT), and cell invasion and migration [29,30]. Therefore, characterization of miRNA expression patterns and their interaction with the target genes in CRC tissues may have substantial value for disease diagnosis, prognosis, and therapy.

MIR452 was identified as a CRC-associated miRNA by miRNA expression profiling of human CRC tissues versus healthy colorectal tissues in our previous study [26]. It was found to be upregulated in human CRC tissues compared with that in the healthy tissues [26]. To confirm this result, we increased the sample size and analyzed the MIR452 expression levels by qRT-PCR. MIR452 levels were mostly elevated (7 out of 10 pair) in additional CRC tissues (Figure S1A). These results indicated that MIR452 expression may be stage-, site-, or microenvironment-specific in CRC tissues.

Twenty-seven genes were finally identified as putative target genes of MIR452 by comparison of the mRNA microarray results with those obtained using bioinformatics algorithms (Table 1). We verified that VEGFA was a direct target gene of MIR452 using dual luciferase reporter assays (Figure 1B). Furthermore, VEGFA mRNA and protein levels were both downregulated upon MIR452 overexpression in CRC cells (Figure 1C) and xenograft tissues (Figure 6C). Although it is not precisely in line with our results, MIR452 expression levels were generally increased in CRC tissues (Figure S1A). In contrast to this result, VEGFA expression levels were generally (8 out of 10 pair) downregulated in primary CRC tumor tissues compared with those in the matched healthy colon tissues (Figure 2A). Additionally, our immunohistochemistry results for the CRC tissues showed that VEGFA expression levels dramatically changed during tumorigenesis. The VEGFA expression level was downregulated at the T1 and T2 stages but upregulated at the T3 stage and then similarly expressed at the T4 stage tumor tissues relative to that in the matched healthy colon tissues (Figure 2B). These results indicate that VEGFA levels negatively correlated with MIR452 levels in CRC tissues.

It is well known that VEGFA is associated with tumor growth, metastasis, and angiogenesis [31-33]. Several miRNAs have been reported to suppress tumor growth, metastasis, and angiogenesis via inhibiting the expression of their target gene VEGFA [34-36]. In this study, we found that MIR452 suppressed CRC cell growth and migration as well as angiogenesis by inhibiting VEGFA expression. Our results showed that MIR452 regulated the VEGFA-mediated VEGFR2 signaling pathway by directly downregulating VEGFA expression in CRC cells (Figure 3). Specifically, MIR452 regulated the VEGFA-VEGFR2-mediated SRC, PLCG1, and MAPK signal pathways (Figure 3C, Figure 4, and Figure 5A,B). Suppression of the VEGFA-mediated VEGFR2-SRC-PTK2 signaling pathway by MIR452 upregulation resulted in decreased cell migration and invasion (Figure 4 and Figure S2). Accumulating evidence has shown that SRC-PTK2 signaling is associated with cell migration and invasion in multiple tumor cells [37-39]. Furthermore, we found that the VEGFA-mediated VEGFR2-KRAS-BRAF-MAPK signaling pathway was suppressed by MIR452 upregulation (Figure 5). These data suggest that the VEGFA-VEGFR2 signaling cascade was downregulated in CRC as a result of increased MIR452 expression in CRC cells. This biological phenomenon involving MIR452-mediated VEGFA-VEGFR2 signaling was confirmed using xenograft tissues in this study (Figure 6). 
Our results using xenograft mouse model showed that the expression level of the angiogenic marker CD31 was significantly decreased by MIR452-mediated VEGFA downregulation (Figure 6C). VEGFA mainly functioned in the extracellular space. We found that the extracellular VEGFA levels were significantly reduced in MIR452-overexpressing CRC cells (Figure 7A). Additionally, our rat aortic ring angiogenesis assay clearly showed that the number of microvessels formed was significantly reduced by MIR452 mimic transfection (Figure 7B). These results strongly indicated that MIR452 regulates angiogenesis in CRC cells by inhibiting VEGFA signaling. In actuality, several cancers including CRC are known to undergo an angiogenic switch with progression, and anti-VEGFA therapy is currently used [40-42]. Our results showed that MIR452 regulates cell proliferation, cell migration, and angiogenesis by direct suppressing VEGFA expression in early CRC progression; therefore, MIR452 may have therapeutic value in relation to human CRC.

\section{Materials and Methods}

\subsection{Patients and Tissue Samples}

The tissue samples used in this study were provided by the Biobank of Wonkwang University Hospital, a member of the National Biobank of Korea. With approval from the institutional review board and informed consent from the subjects (WKIRB-201703-BR-010), we obtained 29 CRC tissues from 18 colon cancer patients ( 9 males and 9 females) and 11 rectal cancer patients ( 8 males and 3 females). The mean ages of the colon cancer patients and rectal cancer patients were 72 years and 73.6 years, respectively. The endogenous MIR452 expression levels were assessed using 10 CRC tissue samples and matched healthy controls. In parallel, 10 CRC samples and matched healthy controls were used to evaluate VEGFA protein levels by western blotting. Additionally, a separate cohort of CRC tissue samples (7 males and 7 females) was used to assess in situ VEGFA expression by immunohistochemistry.

\subsection{Cell Culture}

The human CRC cell lines Caco2, SW480, HT29, HCT116, LoVo, and SW48 were obtained from Korean Cell Line Bank (KCLB, Seoul, Korea) or American Type Culture Collection (ATCC, Manassas, VA, USA). SW480, SW48, HCT116, LoVo, and HT29 cells were cultured at $37^{\circ} \mathrm{C}$ in Roswell Park Memorial Institute Medium (RPMI) 1640 (HyClone, Logan, UT, USA), including 10\% fetal bovine serum (FBS) in a humidified atmosphere of $5 \% \mathrm{CO}_{2}$. Caco2 cells were cultured at $37^{\circ} \mathrm{C}$ in a-MEM (HyClone), including 20\% FBS in a humidified atmosphere of $5 \% \mathrm{CO}_{2}$.

\subsection{RNA Extraction and Quantitative RT-PCR}

RNA extraction and quantitative RT-PCR (qRT-PCR) were carried out as we previously described [26-28]. The differential miRNA expression patterns were validated with qRT-PCR using a TaqMan assay (Applied Biosystems, Waltham, MA, USA), or NCode VILO miRNA cDNA Synthesis kit and EXPRESS SYBR GreenER miRNA qRT-PCR kit (Invitrogen, Carlsbad, CA, USA). The mRNA levels were assessed with qRT-PCR using SYBR Green dye (Applied Biosystems). RNU48 (for TaqMan qRT-PCR) or 5.8S (for SYBR qRT-PCR), and GAPDH were used as endogenous controls of miRNA and mRNA qRT-PCR, respectively. Each sample was run in triplicate. The primers used are listed in Table S2.

\subsection{Transfection and Oligonucleotides}

SW480, HCT116, SW48, and HT29 cells $\left(3 \times 10^{5}\right)$ or Caco2 cells $\left(1.5 \times 10^{5}\right)$ were plated on six-well culture plates or $10 \mathrm{~cm}$ dishes and cultured as described above. The MIR452 mimic (hsa-miR-452, pre-miR miRNA precursor AM17100, product ID: PM12946) and negative control oligonucleotides were commercially synthesized (Ambion, Austin, TX, USA), and used at $50 \mathrm{nmol} / \mathrm{mL}$ for transfections. The transfections were performed with Lipofectamine RNAiMAX (Invitrogen) or siPORT NeoFX 
transfection agent (Ambion) according to the manufacturers' recommendations. The VEGFA small interfering RNA (siRNA) and negative control siRNA transfections were performed according to the manufacturer's protocol (Ambion). The cells were harvested 24-48 $\mathrm{h}$ (for miRNA and mRNA expression) or 48-72 $\mathrm{h}$ (for protein expression) after transfection for functional assays or RNA/protein extraction.

\subsection{Identification of the MIR452 Target Genes by mRNA Expression Profiling}

SW480 and Caco2 cells were transfected with the MIR452 mimic. The total RNAs were isolated $48 \mathrm{~h}$ after transfection. They were amplified and purified using the Illumina Total Prep RNA Amplification Kit (Ambion) according to the manufacturer's instructions, eventually yielding biotinylated complementary RNAs (cRNAs). Hybridization of the samples, signal detection, array scanning, and data analysis and filtering were carried out as previously described [26-28].

\subsection{Luciferase Reporter Assay}

Wild-type or mutant fragments of VEGFA 3'-UTR containing the predicted binding site of MIR452 were amplified by PCR using the primer set shown in Table S2. The luciferase assay results were analyzed as previously described [26-28].

\subsection{MIR452 Target Prediction by Bioinformatics}

The miRNA targets were predicted using the computer-aided algorithms TargetScan (http://www. targetscan.org) and miRWalk (http://www.umm.uni-heidelberg.de/apps/zmf/mirwalk/index.html).

\subsection{Antibodies and Western Blot Analysis}

Protein extraction and western blot analysis were carried out as previously described [26-28]. The blots were then incubated overnight at $4{ }^{\circ} \mathrm{C}$ with the primary antibodies against vascular endothelial growth factor receptor 1 (VEGFR1, also known as FLT1); VEGFR2, SRC-proto-oncogene non-receptor tyrosine kinase (SRC); protein tyrosine kinase 2 (PTK2, also known as FAK1); phospholipase C gamma 1 (PLCG1); KRAS GTPase proto-oncogene (KRAS); mitogen-activated protein kinase 3/1 (MAPK3/1, also known as ERK1/2) (Cell Signaling Technology, Danvers, MA, USA); phosphatidylinositol-4,5-bisphosphate 3-kinase catalytic subunit alpha (PIK3CA, also known as PI3K); B-Raf proto-oncogene, serine/threonine kinase (BRAF); small heat shock protein family B member 1 (HSPB1) (Santa Cruz Biotechnology, Santa Cruz, CA, USA); and VEGFA (Novus Biologicals, Littleton, CO, USA).

\subsection{Cell Proliferation, Cell Migration, and Transwell Migration Assays}

The cell proliferation (viability), cell migration, and Transwell migration (invasion) assays were carried out as previously described [26-28]. The experiments were repeated at least three times in duplicate.

\subsection{Xenograft Model}

The xenograft tumor model was established in mice as we previously described [28]. Briefly, athymic male BALB/c nude mice (6 weeks old, 19-21 g) were purchased from Charles River Technology (Boston, MA, USA) through Orient Bio Inc. (Sungnam, Gyeonggi, South Korea). The MIR452 mimic, siVEGFA, or mock control oligonucleotide was incubated with Lipofectamine RNAiMAX (Invitrogen, Carlsbad, CA, USA) for $15 \mathrm{~min}$ at the ratio of $100 \mathrm{nmol}$ oligonucleotide per $10 \mu \mathrm{L}$ Lipofectamine. Afterward, they were mixed with HT29 cells ( $10^{7}$ cells) in RPMI 1640 medium in a final volume of $200 \mu \mathrm{L}$ for transfection. The transfected cells were then subcutaneously injected into both sides of the posterior flanks of the mice. All surgical and care procedures that were administered to the animals were in accordance with the Animal Care Committee of Wonkwang University (WKU14-47). 


\subsection{Immunohistochemical Analysis}

Immunohistochemical assays were carried out as previously described [43,44]. The antibodies and dilutions used were as follows: monoclonal antibodies against the proliferation marker Ki-67 (MKI67, Thermo Fisher Scientific, Fremont, CA, USA) (1:150) and platelet endothelial cell adhesion molecule 1 (PECAM-1, also known as CD31) (1:150), mouse anti-VEGFA (Novus Biologicals, Littleton, CO, USA) (1:50), and anti-VEGFR2 (Cell Signaling Technology, Danvers, MA, USA) (1:100).

\subsection{Rat Aortic Ring Angiogenesis Assay}

Co-culture experiments were performed in 24-well plates using the Transwell system $(0.4 \mu \mathrm{m}$ pore size) (SPL, Seoul, South Korea), whereby the CRC cells grown in the lower compartments were separated from the MIR452 mimic- or siVEGFA-transfected Caco2 or SW48 cells grown on the overlying filter. All the cells were cultured as monolayers. The support medium was replaced with the assay medium $24 \mathrm{~h}$ before starting the co-culture. The assay medium consisted of the support medium without the additives but included $1 \%$ bovine or human serum. For the co-culture experiments, Transwell chambers were inserted into the wells and the plates were incubated at $37^{\circ} \mathrm{C}$ in $99 \%$ humidity under the standard incubator conditions. Angiogenesis was studied by culturing aortic rings from the thoracic aorta of four-week-old Sprague-Dawley (Orient Bio Inc., Sungnam city, South Korea) rats in a three-dimensional medium made of growth factor-reduced Matrigel (Corning, NY, USA). Briefly, the thoracic aortas were removed from the rats sacrificed by cervical dislocation and immediately transferred to a culture dish containing ice-cold serum-free RPMI 1640 or Alpha-MEM (HyClone, Marlborough, MA, USA). The peri-aortic fibro-adipose tissue was carefully removed with fine microdissecting forceps and iridectomy scissors, paying special attention not to damage the aortic wall. Approximately 15 of $1 \mathrm{~mm}$ long rings were sectioned per aorta and extensively rinsed by five consecutive washes with sterile Phosphate-buffered saline (PBS) at room temperature. In parallel, $150 \mu \mathrm{L}$ of the matrigel was added onto the Transwell filter (the upper chamber in the SPL Transwell system) in each well of a 24 -well plate in a biosafety cabinet. The plate was gently shaken and then incubated at $37^{\circ} \mathrm{C}$ for $30 \mathrm{~min}$ in an ordinary humidified incubator. Afterward, one aorta ring per well was placed onto the middle of each Transwell filter. After incubating the plates for approximately $10 \mathrm{~min}$ back in the incubator, another $150 \mu \mathrm{L}$ of the matrigel per well was added to cover the rings. Then, the plates were returned to the incubator for $30 \mathrm{~min}$. The aorta rings became embedded in the matrigel during this period. Next, $200 \mu \mathrm{L} /$ well Dulbecco Modified Eagle Medium (DMEM) or RPMI 1640 containing $10 \%$ fetal bovine serum (FBS) was added. The plates were incubated at $37^{\circ} \mathrm{C}$ in a humidified environment for one week and examined every other day under a microscope. At least four independent experiments were performed in triplicate.

\subsection{Statistical Analysis}

Sample size was estimated using the $G^{*}$ power software (Version 3.1., Heinrich Heine University, Duesseldorf, Germany). Our data showed that the mean \pm SD of MIR452 levels in CRC tissues was $2.2 \pm 1.1$-fold. In the present study, 10 CRC tissue samples were calculated for $80 \%$ power $(1-\beta)$, $\alpha=0.05$, and anticipated effect size $d=1.09$. Each experiment was repeated at least three times with consistent results. The data are expressed as mean \pm standard deviation (SD). Differences between the groups were assessed using the GraphPad Prism 5.0 statistical software (GraphPad Software, San Diego, CA, USA) or Student's $t$-test. Differences with $p$-values $<0.05$ were considered statistically significant.

\section{Conclusions}

In summary, our study found that MIR452 expression was generally upregulated in the CRC tissues. We identified 27 putative MIR452 target genes using mRNA microarray analysis of MIR452-overexpressing CRC cells and by bioinformatic tools, and showed that VEGFA was a direct target of MIR452. VEGFA expression was upregulated in the early stage CRC tissues. Moreover, 
MIR452 regulated two VEGFA-VEGFR2-mediated signaling pathways (VEGFR2-SRC-PTK2 and VEGFR2-KRAS-BRAF-MAPK), and as a result, MIR452 regulated cell growth, cell migration, and angiogenesis via the VEGFA-VEGFR2 pathway in CRC cells. Although we did not investigate the mechanism of MIR452 upregulation in CRC cells, our results overall suggested that the upregulated MIR452 levels during early CRC progression downregulated VEGFA expression. The diminished extracellular VEGFA levels might, in turn, downregulate VEGFR2-mediated signal pathways. Consequently, they might downregulate cell proliferation, cell migration, and angiogenesis in CRC (Figure 8). Collectively, our results suggested that downregulation of VEGFA expression by increased MIR452 levels in CRC tissues and cells might act as an early inhibitory mechanism against tumor progression in CRC tissues. Therefore, MIR452 might be a promising therapeutic target in early CRC. This possibility, however, needs to be investigated further.

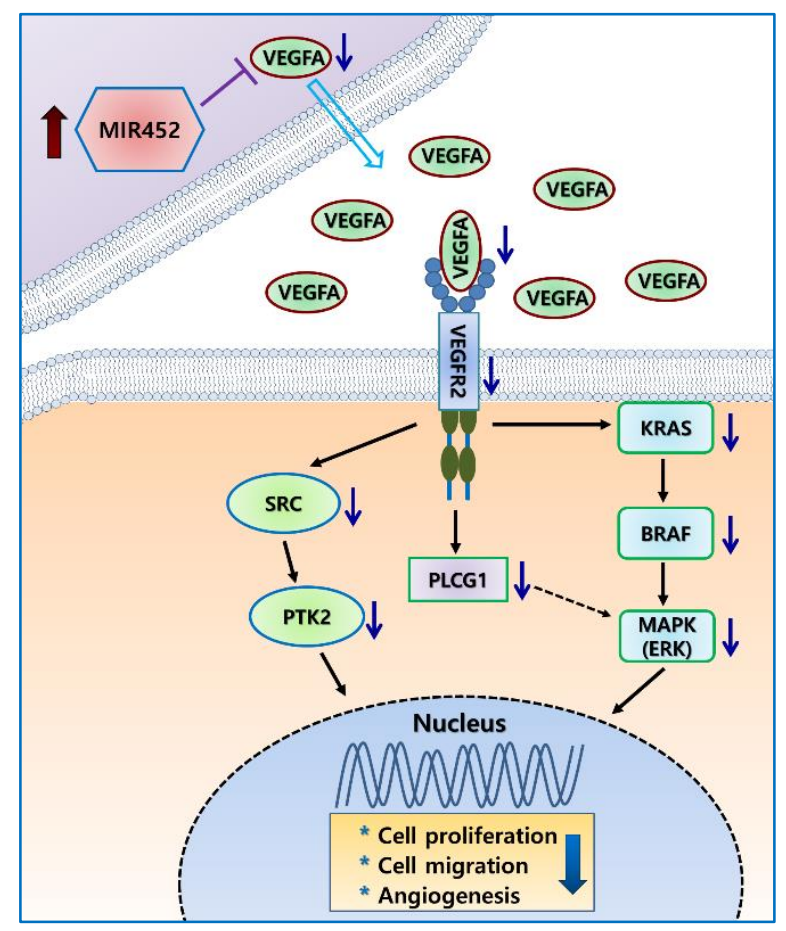

Figure 8. A simple putative mechanism of MIR452 regulation of VEGFA-induced cell proliferation, cell migration, and angiogenesis in human CRC. The increased MIR452 expression in CRC cells led to downregulation of cellular and extracellular VEGFA as well as VEGFR2 levels. The decreased VEGFR2 level caused inhibition of SRC, and, consequently, PTK2 was downregulated. In parallel, KRAS expression was inhibited by the downregulation of VEGFR2; this, in turn, caused inhibition of BRAF and MAPK3/1 (Extracellular signal-regulated kinase, ERK1/2) and led to the expression of growth-promoting genes. Consequently, the elevated MIR452 level in CRC led to inhibition of cell proliferation, cell migration, and angiogenesis. This simple hypothetical mechanism of MIR452-mediated inhibition of angiogenesis was based on the results of previous studies and our study presented herein.

Supplementary Materials: The following are available online at http://www.mdpi.com/2072-6694/11/10/1613/s1. Figure S1. Endogenous MIR452 and VEGFA expression in CRC tissues and cell lines. Table S1. The putative target genes of MIR452 identified and predicted by the microarray analysis from the MIR452 overexpressed cells. Table S2. Primer sequences used for PCR amplification and luciferase assay in this study.

Author Contributions: The authors have made the following declarations about their contributions: S.-C.C. (Soo-Cheon Chae): conceived and designed the experiments. J.S.M. and S.-C.C. (Soo-Cheon Chae): performed the experiments and analyzed the data. W.C.P., S.-C.C. (Suck-Chei Choi), and K.J.Y.: contributed reagents/materials and discussion. S.-C.C. (Soo-Cheon Chae): contributed to draft the manuscript.

Funding: The Basic Science Research Program through the National Research Foundation of Korea (NRF), funded by the Ministry of Science and ICT; grant number: 2017R1A2B4004801. 
Acknowledgments: The research protocol was reviewed and approved by the Ethical Committee of Medical School of Wonkwang University. The biospecimens for this study were provided by the Biobank of Wonkwang University Hospital, a member of the National Biobank of Korea, which is supported by the Ministry of Health and Welfare.

Conflicts of Interest: The authors declare that they have no conflict of interest.

\section{References}

1. Bray, F.; Ferlay, J.; Soerjomataram, I.; Siegel, R.L.; Torre, L.A.; Jemal, A. Global cancer statistics 2018: GLOBOCAN estimates of incidence and mortality worldwide for 36 cancers in 185 countries. CA Cancer J. Clin. 2018, 68, 394-424. [CrossRef] [PubMed]

2. $\mathrm{O}^{\prime}$ keefe, S.J. Diet, microorganisms and their metabolites, and colon cancer. Nat. Rev. Gastroenterol. Hepatol. 2016, 13, 691-706. [CrossRef] [PubMed]

3. Ambros, V. The functions of animal microRNAs. Nature 2004, 431, 350-355. [CrossRef]

4. Bartel, D.P. MicroRNAs: Genomics, biogenesis, mechanism, and function. Cell 2004, 116, 281-297. [CrossRef]

5. Pit, U.; Martin, N.; Rubens, B.; Serge, H.; Elisabeth, L. Hypoxia- and microRNA-induced metabolic reprogramming of tumor-initiating cells. Cells 2019, 8, 528-543.

6. Goradel, N.H.; Mohammadi, N.; Haghi-Aminjan, H.; Farhood, B.; Negahdari, B.; Sahebkar, A. Regulation of tumor angiogenesis by microRNAs: State of the art. J. Cell. Physiol. 2018, 234, 1099-1110. [CrossRef]

7. Serocki, M.; Bartoszewska, S.; Janaszak-Jasiecka, A.; Ochocka, R.J.; Collawn, J.F.; Bartoszewski, R. miRNAs regulate the HIF switch during hypoxia: A novel therapeutic target. Angiogenesis 2018, 21, 183-202. [CrossRef]

8. Garzon, R.; Fabbri, M.; Cimmino, A.; Calin, G.A.; Croce, C.M. MicroRNA expression and function in cancer. Trends Mol. Med. 2005, 12,580-587. [CrossRef]

9. Lu, J.; Getz, G.; Miska, E.A.; Alvarez-Saavedra, E.; Lamb, J.; Peck, D.; Sweet-Cordero, A.; Ebert, B.L.; Mak, R.H.; Ferrando, A.A.; et al. MicroRNA expression profiles classify human cancers. Nature 2005, 435, 834-838. [CrossRef]

10. Braga, E.A.; Fridman, M.V.; Loginov, V.I.; Dmitriev, A.A.; Morozov, S.G. Molecular mechanisms in clear cell renal cell carcinoma: Role of miRNAs and hypermethylated miRNA genes in crucial oncogenic pathways and processes. Front. Genet. 2019, 10, 320. [CrossRef]

11. Kulkarni, P.; Dasgupta, P.; Bhat, N.S.; Shahryari, V.; Shiina, M.; Hashimoto, Y.; Majid, S.; Deng, G.; Saini, S.; Tabatabai, Z.L.; et al. Elevated miR-182-5p associates with renal cancer cell mitotic arrest through diminished MALAT-1 expression. Mol. Cancer Res. 2018, 16, 1750-1760. [CrossRef]

12. Borzi, C.; Calzolari, L.; Ferretti, A.M.; Caleca, L.; Pastorino, U.; Sozzi, G.; Fortunato, O. c-Myc shuttled by tumour-derived extracellular vesicles promotes lung bronchial cell proliferation through miR-19b and miR-92a. Cell Death Dis. 2019, 10, 759. [CrossRef] [PubMed]

13. Wang, Y.F.; Ao, X.; Liu, Y.; Ding, D.; Jiao, W.J.; Yu, Z.; Zhai, W.X.; Dong, S.H.; He, Y.Q.; Guo, H.; et al. MicroRNA-608 Promotes apoptosis in non-small cell lung cancer cells treated with doxorubicin through the inhibition of TFAP4. Front. Genet. 2019, 10, 809. [CrossRef] [PubMed]

14. Zhang, W.C.; Wells, J.M.; Chow, K.H.; Huang, H.; Yuan, M.; Saxena, T.; Melnick, M.A.; Politi, K.; Asara, J.M.; Costa, D.B. miR-147b-mediated TCA cycle dysfunction and pseudohypoxia initiate drug tolerance to EGFR inhibitors in lung adenocarcinoma. Nat. Metab. 2019, 1, 460-474. [CrossRef] [PubMed]

15. Moya, L.; Meijer, J.; Schubert, S.; Matin, F.; Batra, J. Assessment of miR-98-5p, miR-152-3p, miR-326 and miR-4289 expression as biomarker for prostate cancer diagnosis. Int. J. Mol. Sci. 2019, 20, 1154. [CrossRef] [PubMed]

16. Shan, J.; Al-Muftah, M.A.; Al-Kowari, M.K.; Abuaqel, S.W.J.; Al-Rumaihi, K.; Al-Bozom,I.; Li, P.; Chouchane, L. Targeting Wnt/EZH2/microRNA-708 signaling pathway inhibits neuroendocrine differentiation in prostate cancer. Cell Death Discov. 2019, 5, 139. [CrossRef]

17. Zhang, Z.; Pi, J.; Zou, D.; Wang, X.; Xu, J.; Yu, S.; Zhang, T.; Li, F.; Zhang, X.; Zhao, H.; et al. microRNA arm-imbalance in part from complementary targets mediated decay promotes gastric cancer progression. Nat. Commun. 2019, 10, 4397. [CrossRef]

18. Chen, X.L.; Hong, L.L.; Wang, K.L.; Liu, X.; Wang, J.L.; Lei, L.; Xu, Z.Y.; Cheng, X.D.; Ling, Z.Q. Deregulation of CSMD1 targeted by microRNA-10b drives gastric cancer progression through the NF-kB pathway. Int. J. Biol. Sci. 2019, 15, 2075-2086. [CrossRef] 
19. Lu, Z.; Li, X.; Xu, Y.; Chen, M.; Chen, W.; Chen, T.; Tang, Q.; He, Z. microRNA-17 functions as an oncogene by downregulating Smad3 expression in hepatocellular carcinoma. Cell Death Dis. 2019, 10, 723. [CrossRef]

20. Aydin, Y.; Kurt, R.; Song, K.; Lin, D.; Osman, H.; Youngquist, B.; Scott, J.W.; Shores, N.J.; Thevenot, P.; Cohen, A.; et al. Hepatic stress response in HCV infection promotes STAT3-mediated inhibition of HNF4A-miR-122 feedback loop in liver fibrosis and cancer progression. Cancers 2019, 11, 10. [CrossRef]

21. Van Schooneveld, E.; Wouters, M.C.; Van der Auwera, I.; Peeters, D.J.; Wildiers, H.; Van Dam, P.A.; Vergote, I.; Vermeulen, P.B.; Dirix, L.Y.; Van Laere, S.J. Expression profiling of cancerous and normal breast tissues identifies microRNAs that are differentially expressed in serum from patients with (metastatic) breast cancer and healthy volunteers. Breast Cancer Res. 2012, 14, R34. [CrossRef] [PubMed]

22. Liu, L.; Chen, K.; Wu, J.; Shi, L.; Hu, B.; Cheng, S.; Li, M.; Song, L. Downregulation of miR-452 promotes stem-like traits and tumorigenicity of gliomas. Clin. Cancer Res. 2013, 19, 3429-3438. [CrossRef] [PubMed]

23. Zheng, Q.; Sheng, Q.; Jiang, C.; Shu, J.; Chen, J.; Nie, Z.; Lv, Z.; Zhang, Y. MicroRNA-452 promotes tumorigenesis in hepatocellular carcinoma by targeting cyclin-dependent kinase inhibitor 1B. Mol. Cell. Biochem. 2014, 389, 187-195. [CrossRef] [PubMed]

24. Wang, Y.; Toh, H.C.; Chow, P.; Chung, A.Y.F.; Meyers, D.J.; Cole, P.A.; Ooi, L.L.; Lee, C.G. MicroRNA-224 is upregulated in hepatocellular carcinoma through epigenetic mechanisms. FASEB J. 2012, 26, 3032-3041. [CrossRef]

25. Veerla, S.; Lindgren, D.; Kvist, A.; Frigyesi, A.; Staaf, J.; Persson, H.; Liedberg, F.; Chebil, G.; Gudjonsson, S.; Borg, A.; et al. MiRNA expression in urothelial carcinomas: Important roles of miR-10a, miR-222, miR-125b, miR-7 and miR-452 for tumor stage and metastasis, and frequent homozygous losses of miR-31. Int. J. Cancer 2009, 124, 2236-2242. [CrossRef]

26. Mo, J.S.; Alam, K.J.; Kang, I.H.; Park, W.C.; Seo, G.S.; Choi, S.C.; Kim, H.S.; Moon, H.B.; Yun, K.J.; Chae, S.C. MicroRNA 196B regulates FAS-mediated apoptosis in colorectal cancer cells. Oncotarget 2015, 6, 2843-2855. [CrossRef]

27. Mo, J.S.; Alam, K.J.; Kim, H.S.; Lee, Y.M.; Yun, K.J.; Chae, S.C. MicroRNA 429 regulates mucin gene expression and secretion in murine model of colitis. J. Crohns Colitis 2016, 10, 850-859. [CrossRef]

28. Ahmed, D.; Eide, P.W.; Eilertsen, I.A.; Danielsen, S.A.; Eknæs, M.; Hektoen, M.; Lind, G.E.; Lothe, R.A. Epigenetic and genetic features of 24 colon cancer cell lines. Oncogenesis 2013, 2, e71. [CrossRef]

29. Hibner, G.; Kimsa-Furdzik, M.; Francuz, T. Relevance of MicroRNAs as potential diagnostic and prognostic markers in colorectal cancer. Int. J. Mol. Sci. 2018, 27, 19. [CrossRef]

30. To, K.K.; Tong, C.W.; Wu, M.; Cho, W.C. MicroRNAs in the prognosis and therapy of colorectal cancer: From bench to bedside. World J. Gastroenterol. 2018, 24, 2949-2973. [CrossRef]

31. Goel, H.L.; Mercurio, A.M. VEGF targets the tumour cell. Nat. Rev. Cancer 2013, 13, 871-882. [CrossRef] [PubMed]

32. Shibuya, M. Vascular Endothelial Growth Factor (VEGF) and Its Receptor (VEGFR) Signaling in Angiogenesis: A Crucial Target for Anti- and Pro-Angiogenic Therapies. Genes Cancer. 2011, 2, 1097-1105. [CrossRef] [PubMed]

33. Nagy, J.A.; Dvorak, A.M.; Dvorak, H.F. VEGF-A and the induction of pathological angiogenesis. Annu. Rev. Pathol. 2007, 2, 251-275. [CrossRef] [PubMed]

34. Liu, L.; Bi, N.; Wu, L.; Ding, X.; Men, Y.; Zhou, W.; Li, L.; Zhang, W.; Shi, S.; Song, Y.; et al. MicroRNA-29c functions as a tumor suppressor by targeting VEGFA in lung adenocarcinoma. Mol. Cancer 2017, 16, 50. [CrossRef]

35. Ma, H.; Pan, J.S.; Jin, L.X.; Wu, J.; Ren, Y.D.; Chen, P.; Xiao, C.; Han, J. MicroRNA-17 92 inhibits colorectal cancer progression by targeting angiogenesis. Cancer Lett. 2016, 376, 293-302. [CrossRef]

36. Zhang, W.; Zou, C.; Pan, L.; Xu, Y.; Qi, W.; Ma, G.; Hou, Y.; Jiang, P. MicroRNA-140-5p inhibits the progression of colorectal cancer by targeting VEGFA. Cell Physiol. Biochem. 2015, 37, 1123-1133. [CrossRef]

37. Lee, J.J.; van de Ven, R.A.H.; Zaganjor, E.; Ng, M.R.; Barakat, A.; Demmers, J.J.P.G.; Finley, L.W.S.; Gonzalez Herrera, K.N.; Hung, Y.P.; Harris, I.S. Inhibition of epithelial cell migration and Src/FAK signaling by SIRT3. Proc. Natl. Acad. Sci. USA 2018, 115, 7057-7062. [CrossRef]

38. Lu, D.; Yao, Q.; Zhan, C.; Le-Meng, Z.; Liu, H.; Cai, Y.; Tu, C.; Li, X.; Zou, Y.; Zhang, S. MicroRNA-146a promote cell migration and invasion in human colorectal cancer via carboxypeptidase $\mathrm{M} / \mathrm{src}-\mathrm{FAK}$ pathway. Oncotarget 2017, 8, 22674-22684. [CrossRef] 
39. Wang, Y.; Wu, N.; Pang, B.; Tong, D.; Sun, D.; Sun, H.; Zhang, C.; Sun, W.; Meng, X.; Bai, J.; et al. TRIB1 promotes colorectal cancer cell migration and invasion through activation MMP-2 via FAK/Src and ERK pathways. Oncotarget 2017, 8, 47931-47942. [CrossRef]

40. Apte, R.S.; Chen, D.S.; Ferrara, N. VEGF in signaling and disease: Beyond discovery and development. Cell 2019, 176, 1248-1264. [CrossRef]

41. Clarke, J.M.; Hurwitz, H.I. Understanding and targeting resistance to anti-angiogenic therapies. J. Gastrointest. Oncol. 2013, 4, 253-263. [PubMed]

42. Comunanza, V.; Bussolino, F. Therapy for cancer: strategy of combining anti-angiogenic and target therapies. Front. Cell Dev. Biol. 2017, 5, 101. [CrossRef]

43. Alam, K.J.; Mo, J.S.; Han, S.H.; Park, W.C.; Kim, H.S.; Yun, K.J.; Chae, S.C. MicroRNA 375 regulates proliferation and migration of colon cancer cells by suppressing the CTGF-EGFR signaling pathway. Int. J. Cancer 2017, 141, 1614-1629. [CrossRef] [PubMed]

44. Mo, J.S.; Han, S.H.; Yun, K.J.; Chae, S.C. MicroRNA 429 regulates the expression of CHMP5 in the inflammatory colitis and colorectal cancer cells. Inflamm. Res. 2018, 67, 985-996. [CrossRef] [PubMed]

(C) 2019 by the authors. Licensee MDPI, Basel, Switzerland. This article is an open access article distributed under the terms and conditions of the Creative Commons Attribution (CC BY) license (http://creativecommons.org/licenses/by/4.0/). 